\title{
Variables of Suicidal Behavior in Tenerife Years 2011-2012: Proposals for the Prevention
}

\author{
Sergio Manuel Martínez Aguilar', Milagros De la Rosa Hormiga², \\ Juan Manuel Herrera Hernández ${ }^{2}$, Francisco Rodríguez Pulido², \\ Candelaria de la Merced Díaz-González ${ }^{3}$ \\ ${ }^{1}$ Forensic Department, Tenerife, Spain \\ ${ }^{2}$ Universidad de La Laguna, Tenerife, Spain \\ ${ }^{3}$ Servicio Canario de la Salud, Tenerife, Spain \\ Email: mhormiga@ull.es
}

Received 5 March 2014; revised 8 April 2014; accepted 17 April 2014

Copyright (C) 2014 by authors and Scientific Research Publishing Inc.

This work is licensed under the Creative Commons Attribution International License (CC BY). http://creativecommons.org/licenses/by/4.0/

(c) (i) Open Access

\begin{abstract}
Suicide is treated by society as a taboo subject despite it being the leading cause of unnatural death in Spain. The Tenerife Province is ranked $16^{\text {th }}$ among the 52 Spanish provinces for its suicide rate. From 2007 till 2010, the rate increased from 2007 to 2008, then dropped in 2010 . Slight rise occurred in suicide rates in 2010. This rate increased from 2007 to 2008, with a decrease of rate in 2010. Slight rise occurred in suicide rates in 2010. In 2013 the province saw 75 suicides per year. $90 \%-98 \%$ of suicides are closely related to mental disease with the remaining $10 \%$ associated with different poor causes of the subject, according to bibliography. In this retrospective study, it has been found that the highest risk rests with men over 40 years of age in the central and southern part of the island. Among the forms of suicide reported, the most common is hanging followed by jumping from a height. It's important to understand the reasons behind suicidal behavior from a psychosocial perspective, taking into account "unsafe" indicators and individual profiles. The lethal nature of a suicide attempt also depends on the form of suicide adopted and the possibility of a rescue. Specific protocols to prevent suicide should be promoted and discussed between health and social services.
\end{abstract}

\section{Keywords}

Consummated Suicide, Autopsy, Violent Death, Autopsy Psychosocial 


\section{Introduction}

The World Health Organization (2000: 46) states that "suicide is not a disease itself, nor necessarily the manifestation of a disease, but mental disorders are an important factor associated with suicide" [1].

Although there are no indices for predicting suicide attempts, studies have determined set criteria for classifying risk factors. Most interventions will be based on these criteria [2].

- The risk factors considered unchangeable are those that are unrelated to the clinical condition of the subject or their life situation. They are associated with either the subjective or the social group they belong to. These are: heritability, sex, age, marital status, employment and economic status, religious beliefs, social support, and previous suicidal behavior.

- Modifiable risk factors such as those related to social, psychological and psychopathological factors can be modified by clinical or population-based interventions. These are: mental disorder, affective disorders, schizophrenia, anxiety disorder, substances abuse, personality disorders, other mental disorders, physical health, and psychological dimensions.

When speaking of suicidal behavior within the psychopathological examination, usually they are differentiated in: suicidal ideation, suicidal gesture, attempted suicide or completed suicide [3].

From the same scientific resources, it appears that the profile of suicide has the following psio-bio-social variables [2] [3] [4] men older than 60, previous suicide attempts , family history, recent separation , divorce or widowhood, isolation and a perception of being "cut-off" from family and friends, significant anniversaries, unemployment/economic problems, recent humiliating life experience, alcohol or drugs abuse, detailed approach to suicide, depression (manic depression), feelings of guilt, inadequacy and hopelessness, conversation or denigrating behavior, impulsive or hostile personality, delusions or hallucinations, chronic, painful or disabling disease, use of drugs that can cause severe depression, significant changes in the individual's life, immigration and/ or "Ulysses Syndrome".

According to Bertolote, suicidal behavior in a phenomenon characterized by the multi-causality and genesis involves genetic, socio-demographic, clinical and environmental factors [5]. There are various theories proposed, but the important fact is that the link between suicide and mental illness remains one of the strongest: in the Western world, $90 \%$ to $98 \%$ of people who committed suicide had a severe mental disorder. Moreover, one of the most important factors predicting a completed suicide is a prior attempt [6].

According to (Norman and Farberow, 1968; Huguette Bergeron, 1985; Silverman, 2004; Wasserman and Durkee, 2009 in Rocamora 2012) [3] [7], suicide prevention refers to any activity aimed at rescuing those who have made an attempt or who have openly declared to do so. Broadly, prevention can be understood from the promotion of the mental health rehabilitation after a suicide attempt. Among various conceptual models of suicidal behavior prevention, two of the most accepted and used in the literature are: the primary, secondary and tertiary prevention model and also the universal, selective and indicated prevention model.

Regarding the evidence of intervention effectiveness, it should be noted that this is still scarce Martínez, de la Rosa y Herrera [8]. Many studies are descriptive. The chance of finding significant effects in controlled studies is hampered by the low incidence of suicides and the ethical barriers for the use of randomized clinical trials with a control group [2].

According to the abridged report of World Health Organization (2004) on mental disorders prevention the most effective strategies to prevent suicide include prescribing antidepressants to depressed people and reducing the ways to commit suicide. For the prevention of suicidal behavior among youths, a school-based multicomponent approach is recommended [1].

Regarding telephone lines and crisis centers as prevention strategies, the results have not given convincing evidence to indicate any impact on suicide rates, although some results suggest positive effects, such as combining this service with home visits for the elderly [9].

Prevention in school settings has shown no impact on suicidal behavior; there are even indications that it is inadvisable to take this as an option for solving problems. However, direct screening of adolescents using predictors of evidence-based suicide is considered an effective public health strategy to address teen suicide [2].

Reduced access to suicide methods has delivered the strongest results in terms of prevention [10]. This relates to measures such as domestic gas and car exhaust system detoxification, safety precautions adopted for high buildings and bridges, availability, sedatives and analgesics control and restricted access to pesticides.

For all these reasons, what follow are the results of the study on the incidence and prevalence of consum- 
mated suicide on the island of Tenerife between 2011 and 2012 and the technical proposals resulting from the author's reflection and the review discussed above.

\section{Objectives}

- Using autopsy records from 2011 and 2012 to study the prevalence of successful suicide attempts on the island of Tenerife.

- To suggest improvements to our knowledge management in order to conduct a psychological study of suicides and provide emotional support to survivors. A system is needed to identify real and potential risk factors and provide the necessary support to prevent suicidal behavior.

\section{Method}

This is a retrospective study of completed suicide deaths that occurred on the island of Tenerife in 2011 and 2012.

The sources used to conduct this study were Forensic Pathology Service of the Legal Medicine Institute logbooks, in Santa Cruz de Tenerife (SPF-IMLST) where all autopsies, from Tenerife, are centralized.

Analysis and data mining: The statistical treatment used Excel 2012 software, making a descriptive analysis of the occurrence of the variables contained in the autopsy records.

Study variables: sex, age, area of the island, Court of reference, month of the event, day of the event , time of event, day of the week, and mechanism used.

\section{Results}

We can highlight the following results from the Forensic Pathology Service of the Legal Medicine Institute, in Santa Cruz de Tenerife registry (SPF-IMLST) where autopsies are centralized for all Tenerife in the years 20112012 (Tables 1-7).

Table 1. Total autopsies and suicides by sex 2011-2012.

\begin{tabular}{ccccc}
\hline & Autopsies in men & Suicides in men & Autopsies in women & Suicides in women \\
\hline Year 2011 & 307 & 41 & 123 & 23 \\
Year 2012 & 351 & 48 & 117 & 12 \\
\hline
\end{tabular}

Table 2. Distribution of suicide cases by age.

\begin{tabular}{|c|c|c|c|c|c|c|c|c|c|}
\hline & $\begin{array}{c}\text { Minors } 18 \\
\text { years }\end{array}$ & $\begin{array}{c}19 \\
\text { years }\end{array}$ & $\begin{array}{c}20-30 \\
\text { years }\end{array}$ & $\begin{array}{c}31 \text { - } 40 \\
\text { years }\end{array}$ & $\begin{array}{c}41-50 \\
\text { years }\end{array}$ & $\begin{array}{c}51-60 \\
\text { years }\end{array}$ & $\begin{array}{c}61-70 \\
\text { years }\end{array}$ & $\begin{array}{c}71-80 \\
\text { years }\end{array}$ & $\begin{array}{c}\text { More than } \\
80 \text { years }\end{array}$ \\
\hline Year 2011 & 0 & 1 & 4 & 5 & 7 & 14 & 6 & 3 & 2 \\
\hline Year 2012 & 0 & 1 & 9 & 5 & 10 & 13 & 3 & 5 & 2 \\
\hline
\end{tabular}

Table 3. Distribution of suicides geographically within the island.

\begin{tabular}{cccc}
\hline & North Island & South Island & Centre Island \\
\hline Year 2011 & 26 & 12 & 26 \\
Year 2012 & 13 & 19 & 28 \\
\hline
\end{tabular}

Table 4. Distribution of suicide cases depending on the time zone.

\begin{tabular}{cccc} 
& Early morning \\
$1-6$ hours & 13 & $\begin{array}{c}\text { Night } \\
21-24 \text { hours }\end{array}$ & $\begin{array}{c}\text { Afternoon } \\
13-20 \text { hours }\end{array}$ \\
\hline Year 2011 & 10 & 10 & 32 \\
Año 2012 & 9 & 33 & 9 \\
\hline
\end{tabular}


Table 5. Distribution of suicide cases by month of the year.

\begin{tabular}{ccccccccccccc}
\hline & Jan. & Feb. & Mar. & Apr. & May & Jun. & Jul. & Aug. & Sep. & Oct. & Nov. & Dec. \\
\hline Year 2011 & 4 & 6 & 4 & 6 & 4 & 7 & 6 & 8 & 2 & 5 & 4 & 7 \\
Year 2012 & 7 & 2 & 8 & 6 & 5 & 4 & 4 & 7 & 4 & 7 & 8 & 1 \\
\hline
\end{tabular}

Table 6. Distribution of suicides per day in the week in which happen.

\begin{tabular}{cccccccc} 
& Monday & Tuesday & Wednesday & Thursday & Friday & Saturday & Sunday \\
\hline Year 2011 & 14 & 9 & 6 & 9 & 11 & 7 \\
Year 2012 & 12 & 9 & 7 & 5 & 13 & 8 \\
\hline
\end{tabular}

Table 7. Mechanism of suicide.

\begin{tabular}{|c|c|c|}
\hline & Year 2011 & Year 2012 \\
\hline Gas asphyxiation & 2 & 1 \\
\hline Hanging & 24 & 14 \\
\hline Drowning & 4 & 2 \\
\hline Jumping from a height & 20 & 11 \\
\hline Submersion & 1 & 2 \\
\hline Bladed weapon & 3 & 0 \\
\hline Firearm & 2 & 0 \\
\hline Drugs & 4 & 1 \\
\hline Charred & 2 & 2 \\
\hline Polytrauma & 2 & 5 \\
\hline Poison & 1 & 2 \\
\hline Mechanical aphyxia & 0 & 6 \\
\hline Mechanical hanging & 0 & 9 \\
\hline Sunmersion asphyxia & 0 & 1 \\
\hline Ingestion of caustic & 0 & 1 \\
\hline
\end{tabular}

\section{Discussion and Recommendations}

We have to emphasize, from the socio-demographic and case study suicidal behavior profile by sex, ended in the years 2011-2012, in Tenerife, that there is a higher incidence of suicidal behavior in men than in women. The profile of these males is above 40 years of age. They reside in the center and south of the island. They commit suicide generally in the afternoon, in July, August, January and November, choosing Friday and Monday as the days of the Event and as a mechanism mainly hanging and jumping from a height as a second option.

Regarding the profile of women, they are mostly over 40 years old. They reside in the center and south of the island. Suicidal behavior happens any day in the afternoon except Mondays and weekends which are the days of the Event. Jumping from a height is the main mechanism, followed by hanging.

It is factual that there have been many advances in science to address and prevent suicide. However, the results and effectiveness of preventive measures have not yet achieved the desired results. We believe that despite the progress, knowledge, etc., even in the twenty-first century social and health devices (primary and specialty care, social services, third sector, etc.) it is difficult to coordinate effectively and obtain preventive mechanisms and support for people at high risk.

Studies, theories and suicide intervention models seem to establish a high correlation between mental disorder and suicidal behavior. On the other hand it still seems to have failed to improve the synergy and coordination between resources and devices to pay more attention to these people and lead to anticipatory and neutralization of suicidal behavior.

There is a lack of an integrated psycho-biographical management information system in the daily work on the island of Tenerife and rest of Spain. This would enable retrospective analysis by identifying risk factors factors driving a person to an imbalance crisis situation before during and after or, threatened with failure of achieved 
goals (economic, social, religious, psychological, etc.) having symptoms of psychological distress (Rocamora, 2006) [3]. Health and Social resources do not help much on neutralizing and aiding on the life process causing a suicidal behavior and, also, an integrated system which allows a retrospective study of those people up until the date of their death. This study will benefit the development of the analysis of suicide, from psychosocial autopsy to evaluate after death, the state of the victim before they die.

It consists of a retrospective and indirect exploration of the personality and life of the dead person through interviews, in order to clarify the reasons and/or factors associated with their death.

According to Rocamora (2012: 209) [3] "this psychosocial autopsy pursues three main objectives: first, to determine whether forensic death was natural, accidental, suicide or homicide; second, a more clinical analysis of the personal, social, family, and cultural influences resulting in suicide. This second aspect will help us to establish groups more prone to Suicide and to establish more appropriate preventive community measures”. And the third goal is to help families to reconstruct the suicidal death, through the destructive process itself.

So, psychological autopsy is a retrospective evaluation of the death of a person through the information provided by the family, police and doctors. It is therefore a reconstruction of the deceased life and their death in order to determine the personality, mental state and death results (Rocamora, A, 2012: 209) [3].

This process requires training of professionals on how to explore retrospectively and manage professional support techniques to relieve the family's pain and feelings of guilt after their relative's death. Among the existing types of death (natural, accident, suicide and homicide), the last two are the most difficult to overcome in other psychosocial risk factors. Support should be provided by qualified professionals trained in dealing with bereavement and posttraumatic stress to avoid any complications or make it simple helming psychological or psychopathological disorders.

\section{References}

[1] OMS (2000) Prevención del suicidio. Un instrumento para médicos generalistas. Departamento de Salud Mental y Toxicomanías. Organización Mundial de la Salud, Ginebra.

[2] García, J.B., Ubago, J.G. and Ruiz, J.S. (2011) Suicidio y psiquiatría . Fundación Española de Psiquiatría y Salud Mental. Editorial Triacastela, Madrid.

[3] Rocamora, A. (2012) Intervención en crisis en las conductas suicidas. Desclée de Browwe, Bilbao.

[4] Tiffon Nonis, B.-N. (2009) Manual de actuación profesional en psicopatología clínica, criminal y forense: Una dimensión jurídico-legal. Bosch-Penal, Barcelona.

[5] Bertolote, M.J., Desviat, M. and Moreno, A. (Ed.) (2012) Acciones de Salud Mental en la comunidad. Asociación Española de Neuropsiquiatría, Madrid.

[6] Roy, A. (1985) Suicide: A Multidetermined Act. Psychiatric Clinics of North America, 8, 243-250.

[7] Norman, L. and Farberow, D. (1968) Suicide Prevention: A View from the Bridge. Community Mental Health Journal, 4, 469-474. http://dx.doi.org/10.1007/BF01530767

[8] Martínez Aguilar, S., de la Rosa Hormiga, M. and Herrera Hernández, J.M. (2011) El suicidio consumado en la isla de Tenerife. Revista de Trabajo social y Salud, Marzo, 217-236.

[9] De Leo, D., Dell, B.M. and Dwyer, J. (2002) Suicide hmong the Elderly: The Long-Term Impacto a Telephone Support and Assessment Intervention in Northen Italy. The British Journal of Psychiatry, 181, 226-229.

[10] Leenars, A. (2001) Controlling the Environment to Prevent Suicide. In: Wasserman, D., Ed., Suicide, an Unnecessary Death, Martín Dunitz, Londres, 259-264. 